\title{
MINIMALLY INVASIVE INTERVENTIONAL APPROACHES FOR TREATMENT OF FACET JOINT SYNDROME
}

\author{
D. Ferdinandov ${ }^{1,2}$, D. Yankov ${ }^{1,2}$ \\ ${ }^{1}$ Clinic of Neurosurgery, Sv. Ivan Rilski University Hospital - Sofia \\ ${ }^{2}$ Department of Neurosurgery, Faculty of Medicine, Medical University - Sofia
}

\begin{abstract}
The facet syndrome is a unilateral or bilateral pain originating from the intervertebral joint. Its frequency reaches $30 \%$ of the population of patients with low back pain. Inflammation plays a significant role in cartilage degeneration and the development of osteoarthritis, and also significantly contributes to swelling with overstretching of the joint capsule and irritation of nociceptive receptors. Minimally invasive interventional approaches play a significant role in the treatment of facet syndrome. This review systemizes the ways to treat the pain through corticosteroid infiltrations and interventional denervations of the intervertebral joint, which may be complementary techniques. The literature is analyzed and our experience is presented.
\end{abstract}

Key words: facet joint syndrome, corticosteroid infiltration, radiofrequency ablation, cryodenervation, laser ablation

\section{INTRODUCTION}

The facet syndrome is defined as pain originating from any structure of the intervertebral joint - the fibrous capsule, the synovial membrane, the hyaline cartilage and the bone [1]. Its frequency varies between 5 and $15 \%$ of the population of patients with low back pain, and according to some authors reaches as much as 30\% [2-4]. Osteoarthritis and degenerative changes are the leading cause of complaints and, accordingly, occur more and more with age. Other common causes are trauma and stress on the intervertebral joint at work and in sports [5].

\section{Clinical characteristics}

In recent years, the joint facet syndrome has been generally accepted as a separate and specific nosological unit [6]. It has pathological, clinical and instrumental details that clearly define it. The clinical features of the facet syndrome include [7]: unilateral $(20 \%)$ or bilateral $(80 \%)$ low back pain; pain on compression on the affected intervertebral joints; stiffness of the paravertebral muscles; pseudoradicular pain in the buttocks/leg or shoulder/ arm; provocation of complaints in flexion, rotation and to the greatest extent in extension; posture pain; limited mobility.

Inflammation plays a significant role in cartilage degeneration and the development of osteoarthritis, and also contributes significantly to joint capsule edema, receptor irritation, and often debilitating pain $[8,9]$.

\section{DiAgnOSTICS}

For imaging diagnostics, standard radiography is not very useful. The finding is negative in most cases, and it can only show osteoarthritis in an advanced stage but not an inflammatory reaction. Computed tomography (CT) and, to the greatest extent, magnetic resonance imaging (MRI) are the means by which the degeneration of the joint facets can be established and their hypertrophy, arthritic changes and edema can be assessed in details. In addition, they can exclude other diseases such as the presence of disc pathology, infections, rheumatic diseases, fractures, tumors and others.

Of prognostic importance for the success of the interventional procedure is the presence of swelling around the intervertebral joint and exudate in it, which is evident from the enlarged joint space.

\section{TREATMENT}

The treatment of facet syndrome consists of the conservative and interventional approaches [10, 11]. The former are not the subject of this publication and we present the possibilities of minimally invasive intervention techniques.

In the context of the pathogenesis of the facet joint syndrome, corticosteroids suppress systemic inflammation and reduce neuropathic pain [12]. There are many dosage forms for application, including injectable (intravenous, intramuscular, topical), dermal creams and ointments, sprays, tablets, suppositories. 
The application of corticosteroids intraarticularly is the first choice. Only when a sufficiently satisfactory effect cannot be achieved or in case of recurrence of complaints can an alternative method of joint denervation be approached, most often radiofrequency ablation or cryodenervation [13]. However, the so-called ablative procedures (radiofrequency or laser facet denervation, cryoablation, endoscopic neurectomy, etc.) carry the risk of loss of sensitivity in the area of innervation and even of triggering neuropathic pain.

Contraindications to interventional procedures are anticoagulant therapy, malignant tumors, infection, fractures and hypersensitivity to the drugs used [1]. Relative contraindications are many, but for the application of corticosteroids among them should be noted traumatic fractures, diabetes and advanced osteoporosis.

\section{CORTICOSTEROID INFILTRATION}

The local infiltrations with corticosteroid (intra-articular, tendon infiltrations, bursae) in the treatment of non-infectious limited inflammatory condition is routinely used in medical practice and provides relief of symptoms, promotes faster recovery and subsequent return to physical activity. Therefore, the leading approach influencing the inflammatory response and the resulting pain is the widely accepted intra-articular steroid infiltrations [15]. Intervertebral joint interventions are the second most common procedure in specialized pain treatment centers worldwide [16]. The medication block itself also has diagnostic value.

\section{Operative technique}

The operative technique consists in positioning a needle in the space of the intervertebral joint under ultrasound, CT or most often fluoroscopic control. Oblique, anterior-posterior and lateral projections are used. The anatomical landmarks are $2 \mathrm{~cm}$ on the sides of the midline, and for level L4-L5 it is dotted on the line between the two iliac ridges [17]. For level L5-S1, the puncture site is about $2.5 \mathrm{~cm}$ away from the midline. The depth to reach the goal is on average $3-5 \mathrm{~cm}$.

The intra-articular facet infiltration is usually performed under fluoroscopic or CT control [13]. The main advantage of such an intervention is the security of the application but it increases the costs, requires significant hardware resources, takes more time and most of all exposes the patient to X-rays.

Several studies have compared procedures under fluoroscopic and ultrasound control regarding the lumbar facet joints. Similar results have been reported for the two approaches, with X-ray navigation not having a significant advantage in this case $[18,19]$. On the other hand, a series of clinical studies compared intraarticular infiltrations performed by palpation and anatomical landmarks against ultrasound-guided interventions. All authors show that the results are significantly better in the second group of patients [1, 20-22]. The only advantage of applications without image guidance is that they do not require additional equipment and are fast to perform.

In conclusion, the use of ultrasound in the intervention is not associated with radiation exposure and additional health risks, increases efficiency by reducing the possibility of application in the wrong or suboptimal place, can be performed in an outpatient setting as a minimally invasive procedure, allows arbitrarily many projections and is cost effective [21, 23, 24].

\section{Anatomical features}

The facet joint is a true synovial joint that has a capacity of $1.0-2.0 \mathrm{ml}$ of fluid detected by arthrography [25]. In different clinical trials of intra-articular infiltrations have been used different volumes, ranging from $0.25 \mathrm{ml}$ [26] to $3.0 \mathrm{ml}$ [27] and even $8.0 \mathrm{ml}$ [28]. The most commonly used amount of the drug is $1.5 \mathrm{ml}$ [29-35].

On the one hand, large volumes can lead to rupture of the joint capsule and unintentional spread of the medication in adjacent tissues and cause adverse systemic reactions (including positivity in anti-doping controls). On the other hand, the use of an insufficient amount may fail to achieve the desired therapeutic result. It is believed that in both extremes no effective response to pain is achieved [11, 36, 37].

In a clinical study, rupture of the intervertebral joint capsule was found to be very common and occur even in amounts between 1.0 and $2.0 \mathrm{ml}$ [38]. In another, this phenomenon with drug extravasation occurs at volumes above $1.5 \mathrm{ml}$, which are injected into the joint [39]. Based on the above facts, the recommendation in a recently published guide by an international working group is that the amount should not exceed $1.5 \mathrm{ml}$ [40].

\section{Pharmacological features}

The medications used are different, with no exact combination of them. Initial infiltration with a local anesthetic is recommended if analgesia is required or for diagnostic purposes. It is possible to add X-ray contrast at the discretion of the operator. The addition of a corticosteroid, among which triamcinolone acetonide and betamethasone are among the most widely used [1, 41], has been accepted in medical practice with a proven clinical effect. 
The dose of the drug depends on the site of administration, the size of the joint, the degree of inflammation and the amount of synovial fluid, which can be estimated by magnetic resonance imaging. For example, for the knee and shoulder joint it is between 40 and $80 \mathrm{mg}$ triamcinolone or 7 and $14 \mathrm{mg}$ betamethasone, for small joints (including intervertebral), bursae and tendon infiltration - in half, and for soft tissues it is applied respectively $10-20 \mathrm{mg}$ and 2-4 mg [42].

Numerous studies have addressed the pharmacokinetics of corticosteroids according to different routes of administration [43, 44]. Despite widespread use, the degree of systemic absorption and serum levels of various corticosteroids after intra-articular facet joint infiltration are not sufficiently known. The current literature on spinal corticosteroid use has focused on adverse drug interactions [45], fluctuations in serum glucose levels in patients with diabetes [46, 47], and effects on the hypothalamic-pituitary-adrenal axis [48].

The pharmacokinetics after lumbar epidural infiltration of triamcinolone acetonide are known [49]. The elimination half-life is significantly longer than other routes of administration, with a mean of 523 hours after a single application. It was associated, according to the authors, with the redistribution of the depot preparation in epidural adipose tissue. Similar factors may affect corticosteroid elimination following intraarticular facet joint injection.

In another study, intraarticular lumbar facet infiltration of triamcinolone acetonide $1 \mathrm{ml} 40 \mathrm{mg}$ and 0.5 $\mathrm{ml}$ bupivocaine $0.25 \%$ was applied to a total solution of $1.5 \mathrm{ml}$ per joint, which is unlikely to cause capsule rupture and extravasation of the drug. One or two joints (total dose $80 \mathrm{mg}$ ) at the L4-L5 or L5-S1 level were infiltrated. Applications were performed under fluoroscopic control in accordance with best medical practice [31]. Serum concentrations of the main molecule and serum cortisol were studied before application and at fixed time points up to 42 days. Internal standard was also applied. The mean peak of triamcinolone acetonide Cmax of $3.6 \mathrm{mg} / \mathrm{ml}$ was detected 24 hours after administration, with a mean half-life of 213 hours (167-356 hours).

The half-life of triamcinolone acetonide after intra-articular infiltration deserves a comparison of the clearance of the drug from other body parts and fluids. For example, after oral and intravenous administration in humans it is 2.5 and 2.0 hours, respectively. Following intraarticular application to the knee, it varies between 77 and 154 hours [44]. It can be concluded that the half-life in intraarticular infiltration in intervertebral joints is between epidural application and those in large joints.

\section{INTERVENTIONAL APPROACHES}

Minimally invasive surgical techniques aimed at denervation of the zygopophyseal joint have been known for more than 50 years. Rees's [50] initial experience with 2,000 percutaneous procedures is the basis for a rapidly growing enthusiasm for the effectiveness of minimally invasive techniques in the treatment of debilitating lumbar pain. He used a long scalpel which under X-ray control was inserted to the level of the intertransversal ligament, where the nerve structures responsible for the sensation of the intervertebral joint are located. Despite his reported impressive and difficult to reproduce $99.8 \%$ success rate, the procedure was associated with a significant number of postoperative hematomas. In order to reduce the frequency of this complication, radiofrequency facet denervation has been introduced in practice. The pioneer of this procedure was Shealy [5], who in 1976 published his observations on this significantly gentle technique.

The initially reported results coming from the individual pain treatment centers vary considerably, which provokes a more in-depth study of the anatomical substrate of these procedures. Bogduk et al. [51-53] perform systematic cadaveric dissections to localize the so-called articular nerves. The authors compare the objective finding with the obtained radiographs and specify the location of the nerve structures responsible for the sensitivity of the facet joint - the medial branches of the dorsal branch, Fig. 1. Their observations are the basis for the development and success of these procedures to this day.

\section{Operative technique}

The patient is placed on his stomach. If necessary, he can be in the conditions of moderate awake sedation. The level of the intervention is determined radiographically. The site where the cannula will be inserted is infiltrated with a local anesthetic. Under fluoroscopic or, less frequently, CT control the cannula is inserted in depth until it rests on bone - laterally from the zygapophyseal joint and on the upper surface of the transverse process of the lower vertebra. Upon reaching the goal, patients often report provoking "familiar pain". Switch to electrical frequency stimulation to verify the target follows. When the electrode is positioned correctly, patients should confirm that it is in this segment that the pain is typical, regardless of whether the nature and intensity are the same. After a positive test, proceed to local 


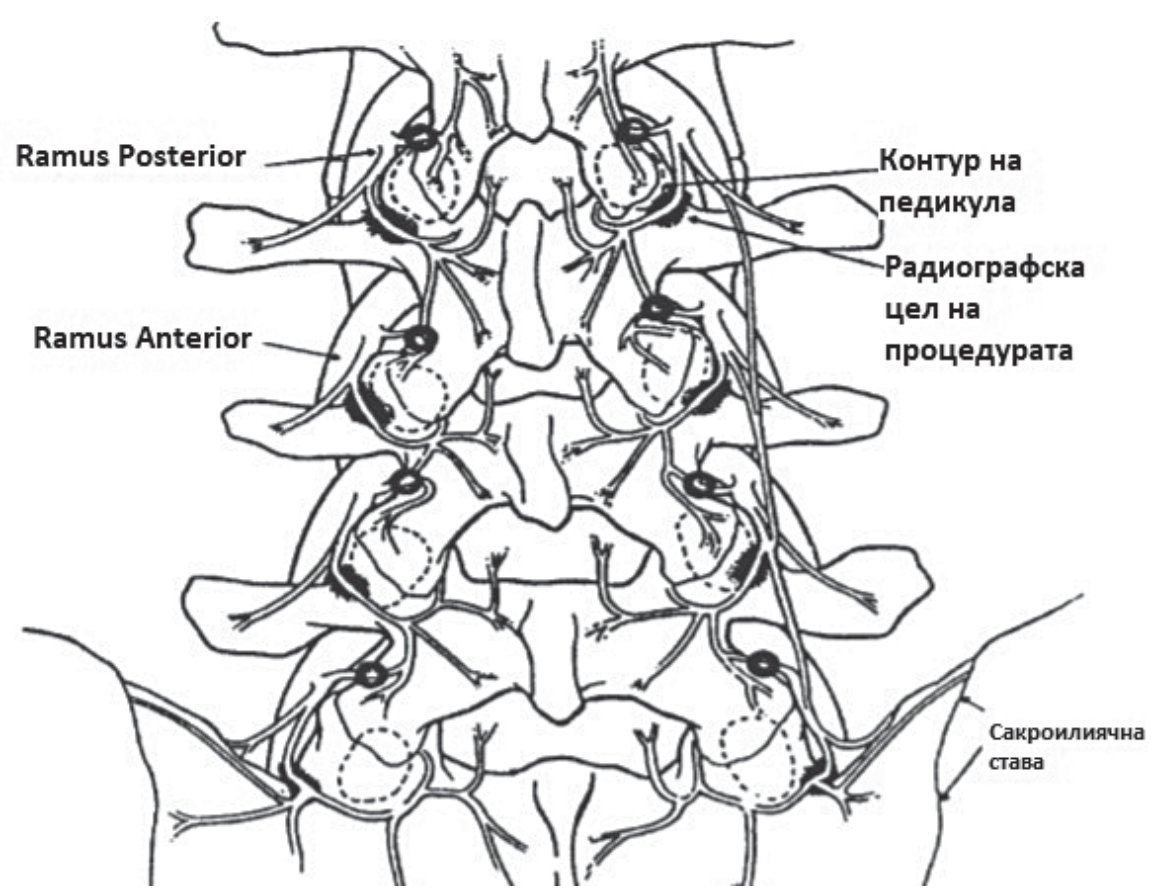

Fig. 1. Anatomical model - target of radiofrequency and cryoablation

temperatures up to $420 \mathrm{C}$. This reduces the risk of damage to adjacent tissues. The theoretical advantage over the conventional protocol is the ability to make a more extensive lesion in nerve structures without causing significant tissue trauma. However, there is still no definitive consensus for a better end result [54].

3. Radiofrequency ablation with cooling. A protocol equivalent to conventional radiofrequency ablation using a cannula with possible additional cooling. This allows the tip of the electrode to reach a temperature of $60-750 \mathrm{C}$ for periods of up to 150 seconds, as a computer monitors and controls the cooling of the surrounding tissues.

infiltration with anesthetic $(2 \mathrm{ml}$ of $1 \%$ lidocaine or $0.5 \%$ bupivacaine). The selected radiofrequency ablation protocol is applied.

If there is severe excruciating pain during the procedure, it should be discontinued and an anesthetic added. In the presence of pain radiating dermatome type to the lower extremities or motor manifestations of the same the intervention is stopped and the electrodes are repositioned. Irradiation to the buttocks and back of the thighs is permissible if it is not of a dermatome nature, and in $99 \%$ of cases it is exhausted to the level of the popliteal fossa. After the procedure, patients are instructed to remain at rest for 3 hours, after which their full mobilization and discharge is possible.

\section{Facet joint denervation protocols}

Today, three main protocols are used in radiofrequency facet denervation:

1. Conventional radiofrequency ablation. The active tip of the electrode is heated in a controlled manner by the continuously supplied radio frequency waves to temperatures of $70-900 \mathrm{C}$. The goal is to create a lesion that engages the nerve structures that conduct pain signals. The damage created is small in volume and is limited by the size of the active tip of the electrode used, not reaching a depth greater than that of the tip of the electrode.

2. Pulse radiofrequency ablation. It is an alternative to the conventional radiofrequency lesion. It is based on intermittent, short pulses of high voltage electric current, which creates local heating to
With this protocol it is possible to create lesions with a diameter of 8-10 $\mathrm{mm}$ in depth from the tip of the electrode, reducing the risk of coagulation and burning of adjacent tissues. Despite the more complex protocol and the increased cost of the procedure compared to conventional radiofrequency ablation, McCormick et al. report a lack of statistically significant benefits in terms of pain relief [55].

It is worth noting that these protocols have not undergone significant changes in recent decades, and evolution has been observed mainly in the equipment used - generators and electrodes. Since the beginning of the 21st century, as an alternative to radiofrequency denervation, other methods for minimally invasive treatment of facet syndrome have been introduced:

1. Cryodenervation. The operative technique corresponds to that used in radio frequency procedures. In this type of intervention, however, a closed probe connected to a cooled carbon dioxide tank is introduced. The local hypothermia created leads to a reversible conduction block in the target nerve structures.

2. Laser facet ablation. A tube is inserted through a small skin incision above the level of the symptomatic intervertebral joint under fluoroscopic control, through which a laser is inserted. The procedure aims to create a lesion of the nerve endings at the symptomatic level and thermodestructive debridement of the pathologically altered zygapophyseal joint.

Regardless of the chosen protocol, it should be noted that unmyelinated $\mathrm{C}$-type fibers with a relation to the pain innervation of the zygapophyseal joint have 
the ability to regenerate, which may require repetition of the intervention in case of recurrence of symptoms.

\section{RESULTS}

There are 6 large randomized clinical trials comparing the effect of radiofrequency denervation procedures with a placebo procedure. Five of the six showed a statistically significant reduction in pain in the group receiving the actual procedure $[54,56-$ 59]. In one of them there is a correlation between a positive preoperative drug block (so-called diagnostic blockade) and a good interventional effect $(P<$ 0.05), and in the absence of effect of the diagnostic block there is an unsatisfactory result of the denervation procedure [59]. Only one of the six studies did not find a statistically significant difference between the two groups - a mean pain reduction of 0.5 points according to VAS in the group selected for real intervention and 0.6 points reduction in the placebo group (60). As already mentioned, there is no significant therapeutic difference between the different protocols of radiofrequency denervation, at the expense of technological and financial burden [54, 55].

A large prospective randomized facet cryoablation study by Birkenmaier et al. also showed a statistically significant pain reduction of $50 \%$ or more $(P<0.0001)$ compared to control groups [61]. The advantages of this type of procedures over radiofrequency are expressed in the practical absence of complications in cryoablation compared to $\sim 1 \%$ of complications reported in radiofrequency procedures - local pain lasting less than 2 weeks $(0.5 \%)$ and one lasting more than 2 weeks $(0.5 \%)$ [62].

There are still no well-structured studies on the efficacy and safety of laser facet ablation.

\section{Discussion}

The efficacy of drug peri- and intrafacet joint infiltrations and minimally invasive surgical interventions is well documented. Comparative analyzes show relatively similar results in performing any of the modalities $(13,63)$. The basis for a good result, as in any surgical procedure, is the correct selection of patients. Predictors of success or failure of this type of procedure are available, such as the most frequently cited: duration of lumbar pain $\geq 3 \mathrm{~m}$, reduction in pain symptoms by at least $50 \%$ with applied local drug (diagnostic) block, lack of other pathology that can to lead to secondary overload and suffering of the facet-joint apparatus (disc herniation, spondylolisthesis, neoplasms, etc.).

The procedure is also applicable for pain symptoms arising from the sacroiliac joint. Two randomized trials from the United States showed a statistically significant superiority of the procedure over placebo intervention $(64,65)$. In these two studies, Cohen and Patel applied cooling radiofrequency ablation to create a larger lesion area required for adequate neuroconductive block of the large sacroiliac joint.

There is no well-structured evidence in the literature to assess the duration of therapeutic effect, but the five randomized trials that reported a positive outcome evaluated efficacy up to 3,6 , and 12 months $[26,54,56,57,59]$. The study of Tekin et al. has the longest follow-up period, reporting a stability at the end of follow-up of 1 year [57].

There is reason to believe that in case of a good result of a radio frequency procedure and subsequent recurrence of complaints, it is possible to repeat the procedure, and the results of retrospective studies show efficacy corresponding to that of the primary procedure $[66,67]$. It should be borne in mind that these are retrospective analyzes and not randomized clinically controlled studies, respectively they have a lower value of evidence.

Cryodenervation creates a reversible conduction block along the course of the respective nerves, which makes the procedure anatomically conservative, but the reported results are more limited at the end of the first year of follow-up [61]. Despite this inadequacy of the procedure due to the practical lack of associated complications, it is possible to repeat it many times. There are currently no analyzes to investigate the effect of re-cryodenervation.

In laser facet joint ablation, in addition to neurolysis, destruction of the pathologically altered anatomical structures responsible for the pain genesis is achieved. This suggests that this procedure would have the most lasting effect on pain. At present, however, there are no studies that objectively assess the therapeutic effect, its duration, the possible complications and the safety profile of the procedure, which is why it is still considered experimental in the treatment of lumbar and sacroiliac pain.

\section{Conclusion}

Facet joint drug blocks and minimally invasive percutaneous neurolysis are easy to apply, rapid, inexpensive, and effective interventions that can be performed in an outpatient setting. They can also be considered as adjuvants to each other. More experience and well-structured randomized trials are needed to evaluate and compare the effect of the relatively new laser facet ablation on established approaches. 


\section{Библиография / References}

1. Karkucak M, Batmaz I, Kerimoglu S, Ayar A. Comparison of clinical outcomes of ultrasonography-guided and blind local injections in facet syndrome: A 6-week randomized controlled trial. J Back Musculoskelet Rehabil. 2019,33(3):431436.DOI: $10.3233 / \mathrm{bmr}-181447$.

2. Schwarzer AC, Aprill CN, Derby R et al. Clinical features of patients with pain stemming from the lumbar zygapophysial joints. Is the lumbar facet syndrome a clinical entity? Spine. 1994 May 15;19(10):1132-7.

3. Schwarzer AC, Wang SC, Bogduk N, et al. Prevalence and clinical features of lumbar zygapophysial joint pain: a study in an Australian population with chronic low back pain. Ann Rheum Dis. 1995 Feb;54(2):100-6.

4. DePalma MJ, Ketchum JM, Saullo T. What is the source of chronic low back pain and does age play a role? Pain Med. $2011 \mathrm{Feb} ; 12(2): 224-33$.

5. Shealy $\mathrm{CN}$. Facet denervation in the management of back and sciatic pain. Clin Orthop Relat Res. 1976 Apr;(115):157-64.

6. Ständer M, März U, Steude U, Tonn JC. [The facet syndrome: frequent cause of chronic backaches]. MMW Fortschr Med. 2006 Oct 26;148(43):33-4.

7. Eisenstein SM, Parry CR. The lumbar facet arthrosis syndrome. Clinical presentation and articular surface changes. J Bone Joint Surg Br. 1987 Jan;69(1):3-7.

8. Berenbaum F. Osteoarthritis as an inflammatory disease (osteoarthritis is not osteoarthrosis!). Osteoarthr Cartil. 2013 Jan;21(1):16-21.

9. Mathiessen A, Conaghan PG. Synovitis in osteoarthritis: current understanding with therapeutic implications. Arthritis Res Ther. 2017 Feb 2;19(1):18.

10. Van Kleef M, Vanelderen P, Cohen SP et al. Pain originating from the lumbar facet joints. Pain Pract. 2010 Oct;10(5):459-69.

11. Cohen SP, Huang JHY, Brummett C. Facet joint pain-advances in patient selection and treatment. Nat Rev Rheumatol. $2013 \mathrm{Feb} ; 9(2): 101-16$.

12. Saunders S. Injection Techniques in Orthopedic and Sports Medicine. Elsevier, New York; 2006.

13. Civelek E, Cansever T, Kabatas S, et al. Comparison of effectiveness of facet joint injection and radiofrequency denervation in chronic low back pain. Turk Neurosurg. 2012;22(2):200-6.

14. Pigozzi F, Di Gianfrancesco A, Zorzoli M, et al. Why glucocorticosteroids should remain in the list of prohibited substances: a sports medicine viewpoint. Int J Immunopathol Pharmacol. 2012 Mar;25(1):19-24.

15. Hooten WM, Cohen SP. Evaluation and Treatment of Low Back Pain: A Clinically Focused Review for Primary Care Specialists. Mayo Clin Proc. 2015 Dec;90(12):1699-718.

16. Manchikanti L, Hirsch JA, Pampati V, Boswell MV. Utilization of Facet Joint and Sacroiliac Joint Interventions in Medicare Population from 2000 to 2014: Explosive Growth Continues! Curr Pain Headache Rep. 2016 Oct;20(10):58.

17. Chakraverty R, Pynsent $P$, Isaacs $K$. Which spinal levels are identified by palpation of the iliac crests and the posterior superior iliac spines? J Anat. 2007 Feb;210(2):232-6.

18. Han SH, Park KD, Cho KR, Park Y. Ultrasound versus fluoroscopy-guided medial branch block for the treatment of lower lumbar facet joint pain: A retrospective comparative study. Medicine (Baltimore). 2017 Apr;96(16):e6655.

19. Yun DH, Kim H-S, Yoo SD, et al. Efficacy of ultrasonography-guided injections in patients with facet syndrome of the low lumbar spine. Ann Rehabil Med. 2012 Feb;36(1):66-71.

20. Özçakar L, Kara M, Chang K-V, Ç, et al. Nineteen reasons why physiatrists should do musculoskeletal ultrasound: EU-
RO-MUSCULUS/USPRM recommendations. Am J Phys Med Rehabil. 2015 Jun;94(6):e45-49.

21. Karkucak M, Kurt M, Özçakar L. Ultrasound Video Demonstration for Lumbar Facet Joint Injection. Am J Phys Med Rehabil. 2016 Oct;95(10):e165-166.

22. Karkucak M, Cilesizoglu N, Capkin E et al. Education and Visual Information Improves Effectiveness of Ultrasound-Guided Local Injections on Shoulder Pain and Associated Anxiety Level: A Randomized Controlled Study. Am J Phys Med Rehabil. 2016 Jan;95(1):9-14.

23. Wu T, Zhao $\mathrm{W}-\mathrm{H}$, Dong $\mathrm{Y}$, et al. Effectiveness of Ultrasound-Guided Versus Fluoroscopy or Computed Tomography Scanning Guidance in Lumbar Facet Joint Injections in Adults With Facet Joint Syndrome: A Meta-Analysis of Controlled Trials. Arch Phys Med Rehabil. 2016;97(9):1558-63.

24. Galiano K, Obwegeser AA, Bodner G, et al. Real-time sonographic imaging for periradicular injections in the lumbar spine: a sonographic anatomic study of a new technique. J Ultrasound Med. 2005 Jan;24(1):33-8.

25. Glover JR. Arthrography of the joints of the lumbar vertebral arches. Orthop Clin North Am. 1977 Jan;8(1):37-42.

26. Van Wijk RMAW, Geurts JWM, Wynne HJ, et al. Radiofrequency denervation of lumbar facet joints in the treatment of chronic low back pain: a randomized, double-blind, sham lesion-controlled trial. Clin J Pain. 2005 Aug;21(4):335-44.

27. Pneumaticos SG, Chatziioannou SN, Hipp JA, et al. Low back pain: prediction of short-term outcome of facet joint injection with bone scintigraphy. Radiology. 2006 Feb;238(2):693-8.

28. Lilius G, Laasonen EM, Myllynen P, e al. Lumbar facet joint syndrome. A randomised clinical trial. J Bone Joint Surg Br. 1989 Aug;71(4):681-4.

29. Dolan AL, Ryan PJ, Arden NK et al. The value of SPECT scans in identifying back pain likely to benefit from facet joint injection. Br J Rheumatol. 1996 Dec;35(12):1269-73.

30. Marks RC, Houston T, Thulbourne T. Facet joint injection and facet nerve block: a randomised comparison in 86 patients with chronic low back pain. Pain. 1992 Jun;49(3):325-8.

31. Dickson RR, Reid JM, Nicholson WT et al. Corticosteroid and Cortisol Serum Levels Following Intra-articular Triamcinolone Acetonide Lumbar Facet Joint Injections. Pain Pract. 2018;18(7):864-70.

32. Revel M, Poiraudeau S, Auleley GR, et al. Capacity of the clinical picture to characterize low back pain relieved by facet joint anesthesia. Proposed criteria to identify patients with painful facet joints. Spine. 1998 Sep 15;23(18):1972-6.

33. Fairbank JC, Park WM, McCall IW, O'Brien JP. Apophyseal injection of local anesthetic as a diagnostic aid in primary low-back pain syndromes. Spine. 1981 Dec;6(6):598-605.

34. Jackson RP, Jacobs RR, Montesano PX. 1988 Volvo award in clinical sciences. Facet joint injection in low-back pain. A prospective statistical study. Spine. 1988 Sep;13(9):966-71.

35. Lewinnek GE, Warfield CA. Facet joint degeneration as a cause of low back pain. Clin Orthop Relat Res. 1986 Dec;(213):216-22.

36. Cohen SP, Doshi TL, Constantinescu OC, et al. Effectiveness of Lumbar Facet Joint Blocks and Predictive Value before Radiofrequency Denervation: The Facet Treatment Study (FACTS), a Randomized, Controlled Clinical Trial. Anesthesiology. 2018;129(3):517-35.

37. Lynch MC, Taylor JF. Facet joint injection for low back pain. A clinical study. J Bone Joint Surg Br. 1986 Jan;68(1):138-41.

38. Dory MA. Arthrography of the lumbar facet joints. Radiology. 1981 Jul;140(1):23-7.

39. Moran R, O'Connell D, Walsh MG. The diagnostic value of facet joint injections. Spine. $1988 \mathrm{Dec} ; 13(12): 1407-10$. 
40. Cohen SP, Bhaskar A, Bhatia A, et al. Consensus practice guidelines on interventions for lumbar facet joint pain from a multispecialty, international working group. Reg Anesth Pain Med. 2020 Apr 3;

41. Misaggi B, Gallazzi M, Colombo M, Ferraro M. Articular facets syndrome: diagnostic grading and treatment options. Eur Spine J. 2009 Jun;18 Suppl 1:49-51.

42. Chang C-W, Huang T-Y, Tseng Y-C, et al. Positive doping results caused by the single-dose local injection of triamcinoIone acetonide. Forensic Sci Int. 2014 Nov;244:1-6. olone acetonide in laboratory animals. Steroids. 1978 Aug;32(1):25-35.

44. Derendorf H, Möllmann H, Grüner A, et al. Pharmacokinetics and pharmacodynamics of glucocorticoid suspensions after intra-articular administration. Clin Pharmacol Ther. 1986 Mar;39(3):313-7.

45. Song Y, Schroeder JR, Bush LM. latrogenic Cushing syndrome and secondary adrenal insufficiency related to concomitant triamcinolone and ritonavir administration: a case report and review. J Int Assoc Provid AIDS Care. 2014 Dec;13(6):511-4.

46. Gonzalez P, Laker SR, Sullivan W, et al. The effects of epidural betamethasone on blood glucose in patients with diabetes mellitus. PM R. 2009 Apr;1(4):340-5.

47. Kim WH, Sim WS, Shin BS, et al. Effects of two different doses of epidural steroid on blood glucose levels and pain control in patients with diabetes mellitus. Pain Physician. 2013 Dec;16(6):557-68.

48. Habib G, Jabbour A, Salman J, et al. The effect of epidural methylprednisolone acetate injection on the hypothalamic-pituitary-adrenal axis. J Clin Anesth. 2013 Dec;25(8):629-33.

49. Hooten WM, Nicholson WT, Gazelka HM, et al. Serum Triamcinolone Levels Following Interlaminar Epidural Injection. Reg Anesth Pain Med. 2016 Feb;41(1):75-9.

50. Rees WS. Multiple bilateral percutaneous rhizolysis. Med J Aust. 1975 Apr 26;1(17):536-7.

51. Bogduk N, Long DM. The anatomy of the so-called "articular nerves" and their relationship to facet denervation in the treatment of low-back pain. J Neurosurg. 1979 Aug;51(2):172-7.

52. Bogduk N, Long DM. Percutaneous lumbar medial branch neurotomy: a modification of facet denervation. Spine. 1980 Apr;5(2):193-200.

53. Bogduk N, Colman RR, Winer CE. An anatomical assessment of the "percutaneous rhizolysis" procedure. Med J Aust. 1977 Mar 19;1(12):397-9.

54. Van Boxem K, Van Eerd M, Brinkhuizen T, et al. Radiofrequency and pulsed radiofrequency treatment of chronic pain syndromes: the available evidence. Pain Pract. 2008 Oct;8(5):385-93.

Постьпил за печат: 29.09.2020 2.
43. Gordon S, Morrison J. The metabolic fate of triamcin-

55. McCormick ZL, Choi H, Reddy R, et al. Randomized prospective trial of cooled versus traditional radiofrequency ablation of the medial branch nerves for the treatment of lumbar facet joint pain. Reg Anesth Pain Med. 2019;44(3):389-97.

56. Nath S, Nath CA, Pettersson K. Percutaneous Lumbar Zygapophysial (Facet) Joint Neurotomy Using Radiofrequency Current, in the Management of Chronic Low Back Pain: A Randomized Double-Blind Trial. Spine. 2008 May;33(12):1291-7.

57. Tekin I, Mirzai H, Ok G, et al. A Comparison of Conventional and Pulsed Radiofrequency Denervation in the Treatment of Chronic Facet Joint Pain: The Clinical Journal of Pain. 2007 Jul;23(6):524-9.

58. Van Wijk RMAW, Geurts JWM, Wynne HJ, et al. Radiofrequency Denervation of Lumbar Facet Joints in the Treatment of Chronic Low Back Pain: A Randomized, Double-Blind, Sham Lesion-Controlled Trial. Clin J Pain. 2005 Jul;21(4):335-44.

59. Gallagher J. Radiofrequency facet joint denervation in the treatment of low back pain : a prospective controlled double-blind study to assess its efficacy. Pain Clin. 1994;7:193-8.

60. Leclaire R, Fortin L, Lambert R, Bergeron YM, Rossignol M. Radiofrequency Facet Joint Denervation in the Treatment of Low Back Pain: A Placebo-Controlled Clinical Trial to Assess Efficacy. Spine. 2001 Jul;26(13):1411-6.

61. Birkenmaier C, Veihelmann A, Trouillier H, et al. Percutaneous cryodenervation of lumbar facet joints: a prospective clinical trial. Int Orthop. 2007 Aug;31(4):525-30.

62. Kornick C, Kramarich SS, Lamer TJ, Todd Sitzman B. Complications of lumbar facet radiofrequency denervation. Spine. 2004 Jun 15;29(12):1352-4.

63. Do KH, Ahn SH, Cho YW, Chang MC. Comparison of intra-articular lumbar facet joint pulsed radiofrequency and intra-articular lumbar facet joint corticosteroid injection for management of lumbar facet joint pain: A randomized controlled trial. Medicine (Baltimore). 2017 Mar;96(13):e6524.

64. Cohen SP, Hurley RW, Buckenmaier CC. Randomized Placebo-Controlled Study Evaluating Lateral Branch Radiofrequency Denervation for Sacroiliac Joint Pain. Anesthesiology. 2008 Aug;109(2):279-88.

65. Patel N, Gross A, Brown L, Gekht G. A randomized, placebo-controlled study to assess the efficacy of lateral branch neurotomy for chronic sacroiliac joint pain. Pain Med. 2012 Mar;13(3):383-98.

66. Schofferman J, Kine G. Effectiveness of repeated radiofrequency neurotomy for lumbar facet pain. Spine. $2004 \mathrm{Nov}$ 1;29(21):2471-3.

67. Son JH, Kim SD, Kim SH, Lim DJ, Park JY. The Efficacy of Repeated Radiofrequency Medial Branch Neurotomy for Lumbar Facet Syndrome. J Korean Neurosurg Soc. 2010 Sep;48(3):240-3.

\section{Submitted: 29.09 .2020}

$\triangle$ Адрес за кореспонденция:
Д-р Дилян Фердинандов, дм
Клиника по неврохирургия
УМБАЛ „Св. Иван Рилски“
бул. „Акад. Иван Гешов“ 15
1431 София
тел.: +359 888678549
e-mail: ferdinandov@gmail.com
ORCID ID: https://orcid.org/0000-0002-0923-612X

$\triangle$ Correspondence address:

Dr. Dilyan Ferdinandov, MD, PhD

Clinic of Neurosurgery, St. Ivan Rilski

University Hospital

15 Acad. Ivan Geshov Blvd.

1431 Sofia, Bulgaria

tel.: +359888678549

e-mail: ferdinandov@gmail.com

ORCID ID: https://orcid.org/0000-0002-0923-612X 